\title{
Web 3.0 and Web 2.0 Technologies in Higher Educational Institute: Methodological Concept towards a Framework Development for Adoption
}

\author{
Kenneth Nwanua Ohei, Roelien Brink \\ Department of Applied Information Systems \\ School of Consumer Intelligence \& Information Systems \\ University of Johannesburg \\ South Africa
}

\begin{abstract}
In the past decades, the method of teaching and learning have centered mostly on the traditional approach (Web 1.0) that promoted teacher directed pedagogical practices. Presently, there is an understanding that the traditional approach is not adequate to effectively address and improve all studentlearning demand or outcomes. The successive incorporation of Web and Web 3.0 tools and applications in universities may serve as additional tools to support educational goals, offering students the affordability and assortments to educational choices and learning platforms. Consequently, educators' inability to fully incorporate these Web 3.0 and Web 2.0 technologies in their teaching and learning practices remains a struggle. This line of reasoning implies that educators still lack the required ICT skills to administer lectures and bridging learning gaps. This study probes Web 3.0 and Web 2.0 in education, using a methodological concept with the aim to develop a framework for the adoption of social software in HEI to help facilitate business processes and can build social presence among students. A mixed method will be appropriate to develop a comprehensive framework needed in Higher Educational Institute (HEI). After research have been conducted, the adoption of Web 3.0/Web 2.0 tools and application will be based on the developed comprehensive framework which is professed to impact positively on pedagogy and style of delivery, improves learning experience, engagement and ultimately, give rise to educational opportunities and easy access to educational contents
\end{abstract}

\section{Introduction}

The concept of Web 3.0 and Web 2.0 technologies and applications in educational institutes has remained noticeable and prominent in the education sector in recent years [17], [5]. Mark off of the New York Times 2006 first envisioned the evolution of Web 3.0 technologies. These instructional ICT technologies enabled by Web 3.0/Web 2.0 tools and applications promises to bring aid to the educational system and universities [4], bearing in mind the nature of the service delivery that universities have to render to their potential learners.

The uses of Web 3.0/Web 2.0 tools are progressively being adopted at various higher learning institutes globally to support the facilitation and learning practices [23]. The arrival of the semantic web has distinctively proposed a turning point about how the digital native might take advantage to benefit from a variety of educational software personal learning environments or personal virtual environments. These environments allow digital natives the possibility of obtaining meaningful information, collaboration and data filtering to suit their needs [23]. Change in educational institute is inevitable, and quite a number of higher educational institutions are beginning to realize that new techniques and methods of teaching and learning is needed to meet the ever-changing needs of the citizens of information-age societies [11], [4].

According to [11] the key element of social revolution and transformation in educational institutes is nothing less than equipping students with general ICT knowledge and skills. This includes technical exposure to inspire lifelong learning; making best and appropriate use of social software technologies for conceptualization, representation, communication; individual development and professional competence.

Several authors [26], [25], [21], [18] confirm that social software tools can play a central role in universities. Web 3.0/Web 2.0 technologies have the ability to transform, accelerate, develop, and improve skills; to encourage and involve learners to participate; to strengthen teaching; and to help universities change.

In view of [30], the adoption and incorporation of Web 3.0/Web 2.0 instructional technologies into webbased educational platforms for business administration processes are fundamental. Further sustained that Web 3.0/Web 2.0 offers four distinctive basic characteristics that can help universities, which relates to intelligence, personalization, interoperability and virtualization nature of Web 3.0/ Web 2.0 to the learning context [30]. These possibilities offer universities platforms towards quality education delivery and a competitive edge to its rivals. 
This study investigates Web 3.0 and Web 2.0 in HEI, through a methodological concept towards developing a comprehensive framework to guide the adoption process. The primitive objective of this study is to explore how the adoption of social software / semantic web and ICT web technologies in HEI can be incorporated with the traditional approach but serve as a complementary tool to improve learning experience and engagement, easy access to educational contents quality education delivery. Furthermore, determines the degree of educators' and students' ICT confidence, readiness and competence to ensure technology usage and innovation in HEI and finally, to identify the challenges that prevents the adoption and usage of social software, ICT and web technologies and its applications in HEI.

\section{Literature background context}

\subsection{Defining social software (Web 2.0) and semantic Web (Web 3.0)}

The rise and evolution of the web in the 1990s gave impetus to web-based revolutions in education. Web 1.0 was the first generation of the web [43]. During this phase, the focus was mainly on building the web, making it accessible and commercializing it for the first time. Web 1.0 was developed and built on a restrictive one-way communication platform [29], which means that in the Web 1.0 age and era, users could only browse, read and retrieve information. In an attempt to help users, engage more collaboratively on the web, the second-generation Web 2.0 was developed by O'Reilly in 2005. This afforded user a much more transformational platform on which to read, write and execute functions.

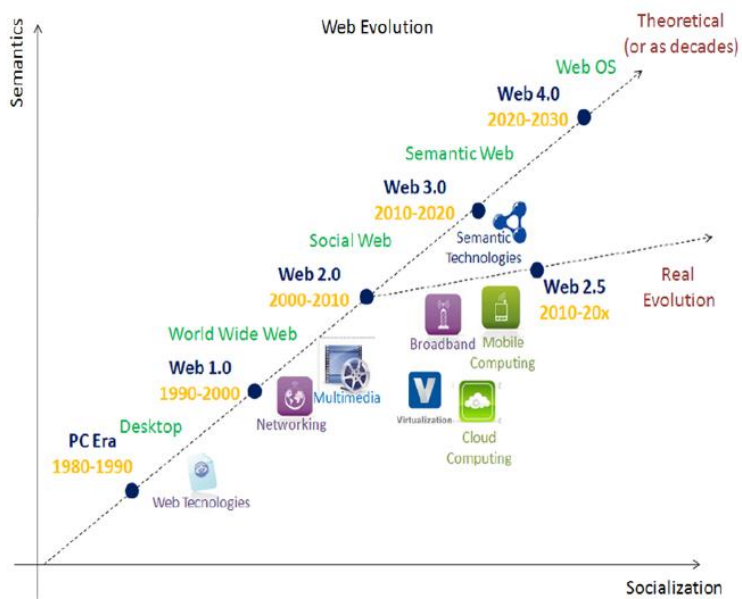

Figure 1. The evolution of the web [49]

The figure is a representation of the evolution and trends of web technologies. Web 3.0 and Web 2.0 can be referred to by different names, which emerged due to their inherent nature and characteristics; some of these for Web 2.0 are "social software", "participatory media" [10], "social digital technologies" and "Web 2.0 technologies". On the other hand, Web 3.0 is referred to as "semantic web". Interestingly, this study will use the concepts of social software and Web 2.0 technologies interchangeably, while semantic web will use for Web 3.0 consistently.

Therefore, the concept of social software and semantic web are an essential leading concept within the context of educational technologies, the focus in recent years has been on the advancement of ICTs for the virtual learning environment (VLE) which is sometimes referred to as learning management system (LMS) [34]. Nowadays, there has been ongoing development and considerable merges and consolidations (for instance the merging of WebCT and Blackboard, Moodle and Sakai, Shareable Content Object Reference Model (SCORM) and many more.

Quite a few of the collaborative ICT tools are thriving. Peer to-peer systems, weblogs, wikis, social software and semantic web have contemporarily emerged and widely been embraced by various universities. Yet these education tools have in many cases also have been downgraded, unsupported or even restricted [39], [41], [33], [45] at education institutions, despite the increasing awareness of its potentials and capabilities of these instructional web tools in education. With the successful integration of social software and ICT tools into education systems, learners can confidently source and browse e-books and have easy access to educational resources and personnel (resource persons, mentors, experts, researchers, professionals, and peers from all over the world) [1], [16]. The use of educational software and application can increase learning intuitiveness, quality business process, and the development of relevant skills needed in the society. Not only will the adoption improve teaching and learning but it will encourage selflearning, problem solving, information seeking and analysis, critical thinking, as well as the ability to communicate, collaborate with peers and educators.

Author [39] maintains that these tools play an essential role in education systems. It not only affects how learners learn, but it offers a dynamic shift in curricula from content-centered to competence-based. Courses distribution has now shifted from an educatorcentered form of distribution to a learner-centered form of distribution. Importantly these ICT tools such as 3D wikis, intelligent tutoring systems, digital libraries, semantic blogs, podcasting and streaming video services, virtual world and avatars and many more can be incorporated into teaching, to provide an inspiring and reliable content that will engage the learners in the learning process [35], [32]. Social software as an instructional ICT web tools are transformational tools which, when adopted efficiently, can enhance learning experience and engagement, enabling the acquisition of general basic skills and techniques [1], [39].

Research evidence suggests that students are more likely to be motivated given the aforementioned tools as opposed to traditional method of learning or the 
stereotype 45-minute lecture [33]. Further emphasis that learning that involves instructional ICT tools would be much more favorable and effective to students than the monotonous monologue lecture situation where the educator just presents lectures from a raised podium and the learners just listen to the educator [33]. Notably, ICT tools enabled by Web 3.0/ Web 2.0 does the task of facilitating intellectual advancement, improving the acquisition of generic intellectual capabilities as needed for lifelong learning in the information society. These tools and applications permit learners to explore and discover, rather than merely listen and remembering [34], [4], [2], [4], [2], [31], [23].

\subsection{Discussion of the prevailing issues}

Higher Education Institutions are confronted with several problems, both in general and education specifically. The facilitation and learning processes should receive special attention. The South African HEI has been experiencing pressure to meet the demands of social transformation and skills exposure needed for the new South Africa in recent decades. There is also the constant burden on improving on strategic policy and delivery performance [44], [25], [34]. South African universities continues to be intensified by the circumstances that many learners who enrolled into universities are novice from the use of ICT tools and would require optimal support to bridge the gaps and the knowledge and skills exposure required. Conversely, the problem with educators' inability to successfully integrate Web 3.0/ Web 2.0 tools in their teaching and learning practices remains. Training educators in the educational uses of social software and ICT tools appears to be a key element of almost every development plan for education and educational reform efforts [40], [26]. In support [11] mentioned that a national survey on ICT usage at universities shows that only very few of educators are optimistic about the potentiality ICT tools. This is an indication that the use ICT technology for learning purposes remains a challenge. With this mind, the efforts to train and equip educators in the educational use of social software tools over decades still persists.

\subsection{Challenges}

Several research studies have shown that effective educator preparation is an important factor for successful adoption and for the sustainability of ICT tools usage in education [21], [15]. Most ICT teacher professional development initiatives tend to focus on technical aspects (i.e., how to use various tools) while pedagogical and instructional issues (i.e., why and how to use the tools to enhance learning) are often taken for granted [26], [41], [39], [33], [42]. As a consequence, the adoption of ICT tools in educational institutes has been determined by the affordability of technology rather than by the demands of pedagogy and didactics of particular subject matter.

In this context, it is important to conceive the educational use of Web 3.0/2.0 not in terms of a special event or an extra tool supplemental to the traditional instruction, but in terms of well-defined pedagogical dimensions [26], [52]. In view of [25], educators' choice to select a suitable teaching and learning method is solely dependent of factors such as the curriculum specifications or module objectives, the aim of the facilitation and learning, the educator's favorite teaching styles, the instructional learning approach of the learner and the nature of the curriculum content [25]. Educators should make use of a method of delivering learning content that suits their paradigm of teaching and learning. It is often said that the educational use of technology offers educators the chance to traverse an entire continuum of possibilities as may be proper to their teaching requirements.

Due to the prominence of social software and semantic web tools in educational settings and society, it is perhaps important to highlight the possible challenges that educators face with regard to the integration of these tools in education [8].

These challenges were divided into several categories. There are various research studies have emerged that categorize these challenges into two main categories [7], namely extrinsic and intrinsic challenges. Extrinsic challenges include access, time, support, resources and training. While Intrinsic challenges are referred to as attitudes, beliefs, practices and resistance.

Other challenges identified in the literature were classified into educator-level challenges and institutional-level challenges. In view of [3] extrinsic challenges as related to organizations as opposed to individuals and intrinsic challenges as related to educators, management and individuals. The like of [8], [7] further classifies and groups the challenges identified according its applicability: whether it relates to individual (educator-level challenges), which involves a lack of time, lack of confidence, readiness, and resistance to accept change; or to the institution (institutional-level challenges), such as a lack of effective training in solving technical problems and a lack of access to resources.

In an effort to establish educators' confidence and readiness in the use of Web 3.0/ Web 2.0 tools in education, the researchers explore all of these categories. The first category as mentioned above deals with educator-level challenges, which is associated to lack of confidence among educators, followed by resistance to accept change and a lack of educator competence. Secondly, the researchers look into the institutional-level challenges. The following sections and subsections provide a detailed discussion on each concept highlighted. 


\subsubsection{Educator-level challenges.}

Regardless of increased computer access and technology development support, technological tools have not been fully harnessed to administer the types of teaching that is supposed to be most influential [26], [17]. Regrettably, research shows that the use of Web 3.0/ Web 2.0 tools tends to be of a poor standard (Maddux \& Johnson, 2006). In this section, the researchers view the adoption of Web 3.0/ Web 2.0 from the lens of an educator as mediator of transformation. There is no doubt that educators have improved their individual and skilled uses of technologies, yet many still struggles [17].

\subsubsection{Educators' lack of confidence}

The most prevalent challenge that most educators commonly face with when using Web 3.0/ Web 2.0 and ICT tools in lecture halls is linked to a lack of ICT confidence [53]. The author [8] acknowledges this issue of educators' lack of ICT confidence as a background factor that becomes a challenge. Advent research reveals that one of the reasons for the lack of confidence found in educators is fear of inappropriate use or failure to use ICT tools. In support of this claim [6] added another factor that hinders educators from using Web 3.0/ Web 2.0 technologies in their teaching and learning is the lack ICT knowledge. This make them nervous about using instructional tools and application in facilitating learning.

The report on [7] concludes that educators who do not have confidence in themselves or who are not skilled in the use of ICT technologies often struggle and be afraid or anxiety and nervousness to make use of such tools in front of their subjects (student). Perhaps they fear that their students may be more knowledgeable than they are in lecture halls.

Therefore, lack of confidence and inexperience with the use of technological tools affect educators' enthusiasm to teach using these tools [8]. Educators who have confidence when using Web 3.0/ Web 2.0 tools understand its usefulness and capitalize on it benefits. In addition, [17] believe that if educators want to prepare their students for lifelong learning and being technologically inclined, educators should at least possess some these basic ICT skills. As it is one of the fundamental requirements as reflected in the NETS-T [teacher/educator] criteria [24].

Authors continued to reveal that where educators have acquired the relevant knowledge, confidence, and belief, they will have powerful skills that would allow them to integrate technology into their lecture halls in significant ways. However, for a majority of educators, this is still not enough, as research shows that advanced educators are easily overwhelmed by pressure to fit in [50]. The next section highlights the lack of ICT competence among educators.

\subsubsection{Lack of educators' competence}

According to [22] who described competence as the capability to syndicate and apply appropriate characteristics to specific tasks in certain contexts. These characteristics comprise high levels of understanding, high standards, skill, individual dispositions, thoughtfulness and competencies, and the capacity apply combinations of these characteristics in practice in an applicable manner.

In pedagogical context, ICT competence refers to what an educator should be acquainted with and be able to do with technology in professional practice. The lack of ICT competence is another challenge that educators face in the adoption of Web 3.0/ Web 2.0 for teaching purposes. It is in turn linked to educators' confidence. A research study conducted in Australia reveals that many educators lack skills and knowledge, although this report differs from country to country [8]. Research studies have demonstrated that in underdeveloped countries, a lack of technological competence is a major hindrance to educators' acceptance and integration of ICT skills.

Lack of ICT skills was perceived to be the main reason for not using Web 3.0/ Web 2.0 instructional web technologies in education in Syria and Saudi Arabia. A lack of skills is a compelling factor that hinders educators from using ICT tools in education [8].

\subsubsection{Educator resistance}

In an effort to fully understand educators' resistance to the use of technology, we take a closer look at the positive and negative attitudes and perceptions of the education. Attitudes contribute to educators' technical resistance. [48] views attitude from a mental perspective separate from the environmental impacts and the professional variables that equip an educator to use ICT in teaching and learning.

The technology acceptance model (TAM) proposed by [14] explains these intrapersonal aspects in terms of perceived usefulness and perceived ease of use or control [48]. Perceived usefulness is described as the degree to which an educator has confidence that using a specific [48] technologies will improve his or her knowledge. The perceived ease of use may be described as the degree to which one has confidence when using a certain technological tool.

In other words, a positive attitude leads to engagement/commitment behaviours, while the negative attitude leads to resistance or avoidance. Hence psychological readiness for Web 3.0/Web 2.0 tools adoption deals with the individual sensitivities, beliefs, attitudes and motives [48].

Educators' resistance to accept change is another challenge. An inherent resistance to change has been perceived as one of the issues that most educators face. Educators' attitudes towards the use of new technological tools in education remain an obstacle for Web 3.0/Web 2.0 and ICT integration [8]. Resistance to 
change may be exacerbated by other issues, such a lack of technical support, educator proficiency or time for development.

\subsection{Institutional-level challenges}

\subsubsection{Lack of time}

Time and skills are key institutional level challenges that sometimes prohibit educators from adopting these tools in teaching and learning [14]. The authors indicate that most institutional policies and procedures serve as hindrances to technology-improved delivery. [51] sustains that time factors were issues found in most educational contexts. Authors maintained that the issue of a lack of time affects educators' capacity to function effectively in their respective jobs. It is clear that educators need adequate time. They need time to carry out their duties such as preparing for lectures and ample time for development support and training programme on using technological applications to facilitate learning [7], [3].

\subsubsection{Lack of operational training}

Educational institutions regard ineffective development support with the use of technology as a major challenge. According [6] and [47] aver that the most common challenges educators encounter is a lack of effective training. Moreover, the challenge of operational training is indeed multifaceted, so it is vital to examine the components that constitute effective operational training support [8]. These components include time for training, educational training and skills training.

In view of [27] who state that just like institutions are transforming rapidly, so is technology. We live in an era of growing access to technology and a progression of technology into educating, learning and the professional improvement of educators. Different kinds of knowledge can be gained during skills development training, instilling and ensuring professional advancement. Skills development training requires a process of applying practices or techniques that involve new skills and alternatives. One of the main hindrances to educators' use of Web 3.0/Web 2.0 applications in administering teaching to learners is the lack of training, insufficient number of in-service training programmes; and inadequate educator training support [7].

In line with the above claim, [51] maintained that once new technologies have to be incorporated in the lecture hall, educators have to be prepared for the use of these specific ICTs. Educators have to do more preparation to advance the applicable skills, information, attitude and confidence concerning the effective use of Web 3.0/Web 2.0 and ICT tools to support teaching and learning in their subjects.

\subsubsection{Lack of accessibility to resources and technical support}

Quite a number of research studies have indicated that a lack of access to resources is another problem that discourages educators from actively becoming involved in adopting new ICT tools and applications into the learning environment [8], [7], [28]. Many educators have limited access to ICT infrastructure and resources. They often have to share ICT infrastructures with fellow educators. Authors argues that sometimes the inaccessibility of ICT infrastructure resources is not due to the unavailability of the hardware and software or other ICT resources within the institution. In some cases, it has to do with issues such as the maladministration of resources, flawed or poor-quality hardware, unsuitable software, or a lack of individual access for educators ([8], [28]. Challenges associated with a lack of access can differ from country to country.

Furthermore, [28] identify infrastructural challenges such as problems with broadband, an inadequate number of computers, inadequate peripherals, inadequate copies of software, and deficient simultaneous internet access. These factors hamper Web 3.0/Web 2.0 adoption. Without access to resources, good technical support and ICT infrastructure in the lecture halls in place, educators cannot overcome the challenges that discourage them from using Web 3.0/Web 2.0. Lack of technical support can also prevent educators from effectively integrating Web 3.0/Web 2.0 in education [9].

\section{Research design and methodology}

In a research study, the research problem mainly is the key determinant of the type of research approach that would be applicable. A study can either be conducted using a qualitative, quantitative or combination of both, however, none of these methods is intrinsically better than the other. In this instance, a mixed method research design will be more appropriate in this study. Notably, the selection of a mixed method research is influenced by the research paradigm and approach. This research method is most suitable due to its usefulness when dealing with a precise research question and realizing a precise research objective. The research objective and research questions in this study cannot be resolve by using only one research method [13].

The justification of approaching a mixed method research is that it can be applied at any point during a research endeavor; it can fit into any structure; can function at any level of investigation; in any proportion; with any instrument or methods; and with either qualitative or quantitative data analysis [30], [13]. Furthermore, in this study, an in-depth research will be undertaken on literature relevant to the social software for ICT web technologies and application at HEI. A systematic, substantial and insightful discussion of 
related literature will be done to builds logical foundations for this study. Thus, the research and analysis on literature will direct, guide, elucidate and recognize material that supports evidence of weaknesses and strengths of social software as an instructional ICT web tool in HEI. In addition, the study will employ both pragmatist and connectivist philosophical assumptions that will ground the study.

Furthermore, what is important is that the study will use a nested or embedded approach, as this will enable the researchers to gain insight and advances pathway of addressing data collection, analysis and the validity of the research [13]. Nonetheless, this strategy attempts to appreciate the qualitative results by quantitative means. The researchers chose this strategy of enquiry because it employs the quantitative data to expound on the qualitative results [13]. This will imply that the second approach of data collection (quantitative) as shown in Figure 2 below is entrenched or embedded in the study and acts as a support to qualitative findings. This strategy is deemed fit for this research study as it enables the researchers to achieve the underlying research objectives by identifying the problem, explaining its nature and determining its scope.

\subsection{Data collection methods}

A structured interview and questionnaire will be using to collect data, the interviews will be directed among educators and questionnaires directed to students across three universities namely; the North-West University that consists of Mafikeng, Potchefstroom \& Vaal Triangle Campuses; University of South Africa (UNISA) and University of Pretoria. The interviews will focus on academic staff members from different academic disciplines, namely Information Systems, Computer Sciences, School of Computing, and Informatics who are involved in social software and ICT web technologies and application at South African universities.

A purposive and snowball sampling technique will be used to select academic staff members from the universities stated above. Concerning questionnaires data collection approach, a probability sampling technique will be using to select students across these universities. The sampling will result in five (5) individual interviews from each university and interview participants will amount to 20 participants across these universities. Nine hundred and sixty-nine (969) correspondents will be involved across the selected universities.

During data analysis, the study will employ diverse analytical software tools such as ATLAS.ti, Statistical Package for the Social Science (SPSS) and Microsoft Excel. In a qualitative data analysis, these coding steps namely open coding, axial coding and selective coding will be undertaken as mentioned. The next section provides a detailed rationale behind using mixed methods, bearing in mind that mixed method approach implies the combined use of qualitative and quantitative method. The top-level research strategy (Figure 2) provides the research process and direction undertaken to collect the relevant data to address the research problem as discussed above.

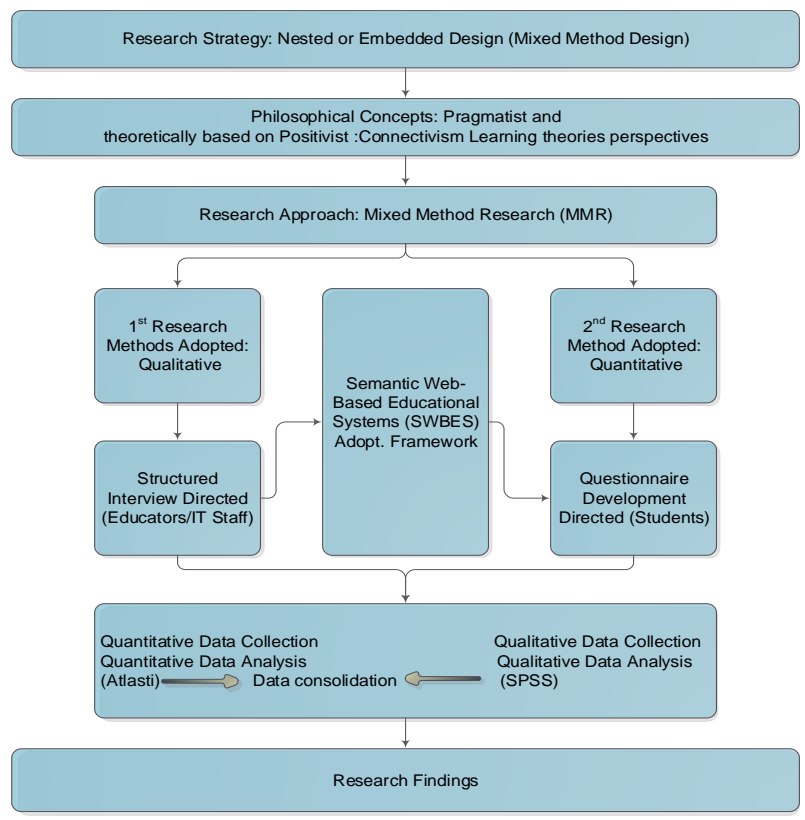

Figure 2. Top-level research strategy

\section{Conceptual framework}

A theoretical framework is a conceptualization of a specific complex research phenomenon, including the salient constructs and their interconnection. In the information systems research domain, a framework helps researchers and practitioners to understand and represent information systems contexts. Guiding ideologies for the concepts that are involved is establish by means of a framework [36]. A framework is often view as road map that provides soundness to the practical investigation in a research activity. Moreover [46] add that it is an organized technique of expressing how and why a research inquiry takes effect, and how to understand its activities.

In this study, the framework is a sort of transitional theory that seeks to guide the researchers in all parts of this research and to align problem statement and research questions so that the research ultimately comes together into a whole. Therefore, this section assesses the existing technological tools and applications used in learning and business administration processes. The focus is on whether social software and ICT web technology tools and applications will be effective to support collective, interactive, constructive and transformative learning. The contribution of this discourse is to develop a comprehensive framework for the adoption and integration of SS applications tools in 
education to allow learners to choose how and where they want to learn [39].

The section is structure as follows: a detailed framework as discussed above followed with a presentation of an overview of the proposed diagrammatic framework. Next is a brief detailing of all the nodes represented in the proposed framework. This proposed framework analysis in Figure 3 indicates the process undertaken to analyze the relevant data for the research. Each aspect of the research process will be discussed in brief following the framework. Apparently, this diagrammatic framework in Figure 3 develops the concepts involved and expands the body of knowledge. More specifically, the benefit of this proposed framework is that it will broaden the insight into the phenomena that is studied. It brings understanding and exposes the theoretical foundations of complex research phenomena through visual exposition. Additionally, the framework facilitates web information modelling, facilitate semantic annotation and information retrieval, enable system interoperability, personalization, virtualization, intelligent agent and enhance information quality [46].

The proposed diagrammatic framework proposes four precise aspects that govern institutional transition and schematically exemplified by a tree structure. The first aspect in the diagrammatic representation of the framework illustrates the conditions for transitioning and addresses the expected educational impact. The second aspect deals with the significance and facilitation of learning through social software/ semantic web tutoring agent. The third and fourth aspects deal with the controversies surrounding social software / semantic web \& ICT investments and their effects following the adoption process. The transition involves the adoption of semantic web-based educational systems (WBES) web content and it complements the four core nodes, namely educational impact, social software / semantic web tutoring agent impact, controversies, and ICT investment considerations.

The diagrammatic representation categorizes the educational impact of the basic structure into four parts, namely innovation/collaboration, content-drivenness, information quality and transformation/sustainability. The social software / semantic web tutoring agent root is categorizing into six parts, namely the virtual 3D world of wikis/podcasts/vodcasts/folksonomies; intelligent search engines; semantic digital libraries; intelligent tutoring system; macro/semantic blogging and RSS filters/mash-up/social networks. These parts are education delivery processes and will be briefly discussed.

The third aspect governing the adoption of (SWBES) relates to the controversies root, which is categorize into four parts; security issues, ethical and legal issues, human factors and ICT infrastructure). The security issues relate to privacy issues and intellectual property rights. Ethical issues include the misuse/illegal use of social software application tools. Human factors entail behavioral patterns, technophobia and acceptance/willingness to use these tools. The fourth aspect, which is social software and ICT investments and its implication, were categorized into costs, benefits, risks arising from software crises and flexibility. All the components of this framework will be discussed in brief as the study proceeds.

\section{Discussion of the proposed framework}

\subsection{Semantic-Web-Based Educational Systems (SWBES)}

The first part of the discussion focuses on the positive aspects of the framework presented above. Such a framework may assist different users (learners, educators and the institution itself) to achieve their educational goals. The framework includes a new cohort of SWBES that are useful for enhancing and improving business processes and that improve the quality of service delivery with social software / semantic web technology [21].

The two dotted double-edged arrows in the framework point towards the educational impact, and social software / semantic web tutoring agent root signifies the dynamic between the learners and educators/institution in the SWBES. The learner's role involves the eagerness of learners to collaborate with pedagogical technologies in an attempt to develop their knowledge and to achieve the student's learning goals [16]. This communication/interaction is attainable through personalized and adaptable educational Web 3.0 content.

The educators'/institution role entail numerous pedagogical events involved in SWBES; this includes collaboration abilities, information quality, contentdrivenness and transformation of intuitive teaching and learning, curriculum design and authoring. Adding to this, the educators play a role in assessing learners' collaborations (problem solving, assessment etc.) and helping learners to construct or develop approaches that best suit them. The processes described above are bidirectional and interlinked as learners and educators/institutions are all key components in the SWBES framework [20], [16]. The next section deals with the transitioning aspect, which includes the educational impact of the adoption of SWBES and ICT into education.

\subsection{Educational impact}

As stated above, the root representing education has four parts, namely innovation/collaboration, contentdrivenness, information quality and transformation/sustainability [20], [16]. 


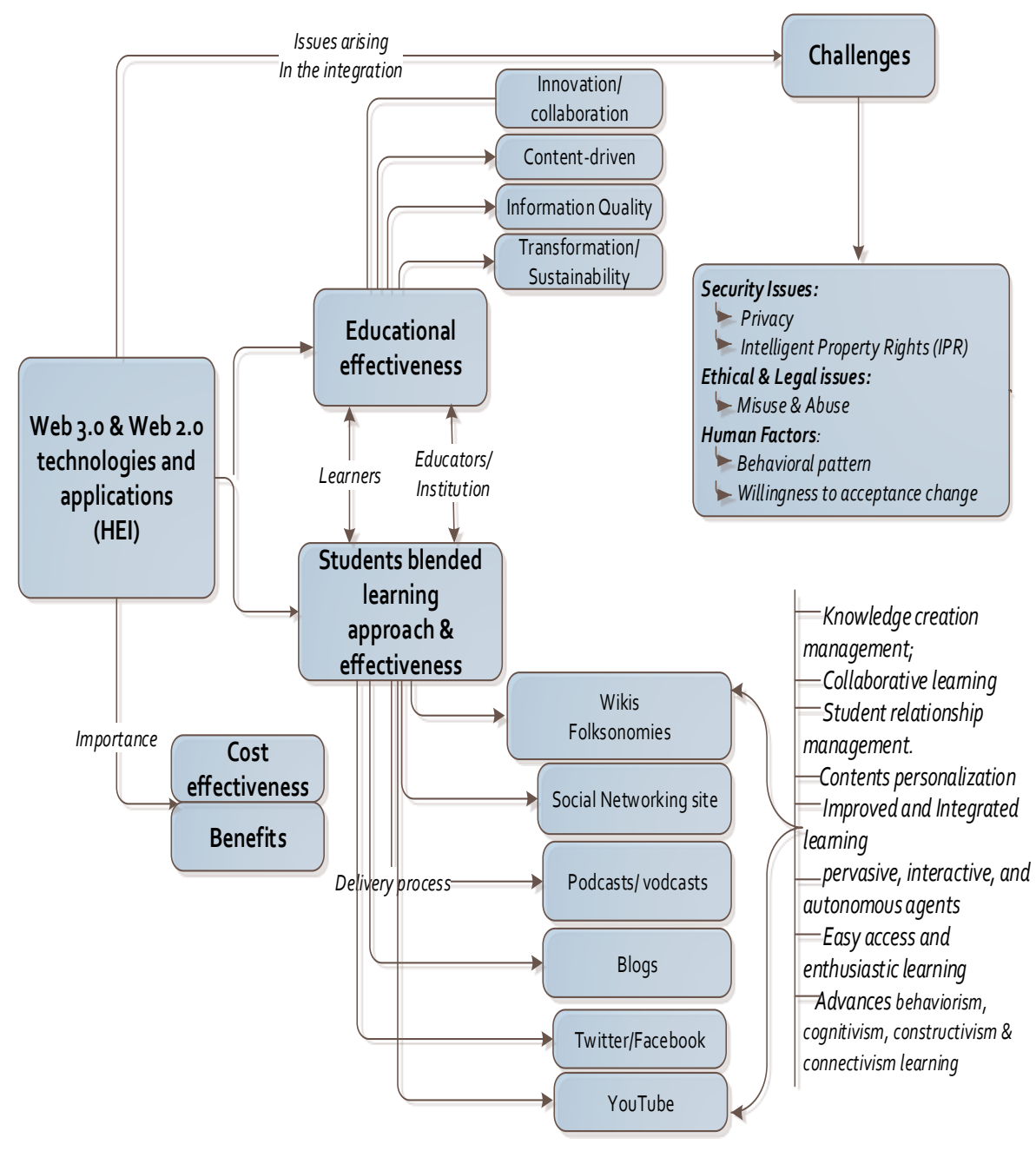

Figure 3. Diagrammatic framework for social software and semantic web adoption Adopted [16]

\subsubsection{Innovation/collaboration}

Innovation refers to the use of technologies associated with social software / semantic web and ICT application tools to support semantic content innovation in education. It involves semantic content representations, pedagogical curriculum course design with accuracy and reliability, allowing instinctive thinking, idea-based searches, and process configuration and information discovery.

\subsubsection{Content-drivenness}

This aspect relates to content generation, distribution, reposition, reuse, retrieval and distribution. The content generation processes result in improved enactment, with delivery lagging behind. Progressive automation allows networking to be content and userdirected.

\subsubsection{The information quality category}

The information quality category: Information quality has a direct impact on educational success and profitability. Good quality information is associated with certain traits (applicability, assessment, benefit, timeliness, comprehensiveness and capacity), proper representation (clarification, ease of comprehension, concise and reliable representation), userfriendliness/access, safety, and inherent document qualities (correctness, impartiality and consistency) as illustrated in the Figure 3.

\subsubsection{Transformation/sustainability}

This aspect is associated with educational change away from a highly centralized model of learning to the inclusion of new ICT technological tools enabled by social software / semantic web, allowing institutional developments, new functions, standards and control. 
When compared with the web technologies of the past, the current web technologies have improved web application functionalities and have transformed data management and information discovery. It is sensible to reflect on the present and potential impact of internet growth, such as on mode of delivery and learning assessments.

In terms of learning assessment, the intelligent tutoring/tagging agent help learners and educators to devote less time to searching unlimited amounts of data. Several authors advise that semantically intelligent searching can address some of the concerns about digital literacy and information management [20], [37].

Web 3.0 combined with Web 2.0 technologies have a far-reaching effect on educational context. Both inspires cooperative intelligence, support interoperability, improve sustainability, and bring a revolution that can give an institution a competitive advantage [16]. The next section presents the second aspect, which deals with the impact and facilitation of learning through social software / semantic web tutoring agents. The tutoring agent impact entails the methods of delivery, followed by the third and fourth aspects.

\subsection{Web 3.0 and Web 2.0 as tutoring agent impact in HEI}

In the proposed framework, the social software / semantic web tutoring agent branches out into six parts, namely the virtual 3D world, wikis/podcasts/vodcast/folksonomies; intelligent search engines; semantic digital libraries; intelligent tutoring systems; macro/semantic blogging and RSS filters/mash-up/social network.

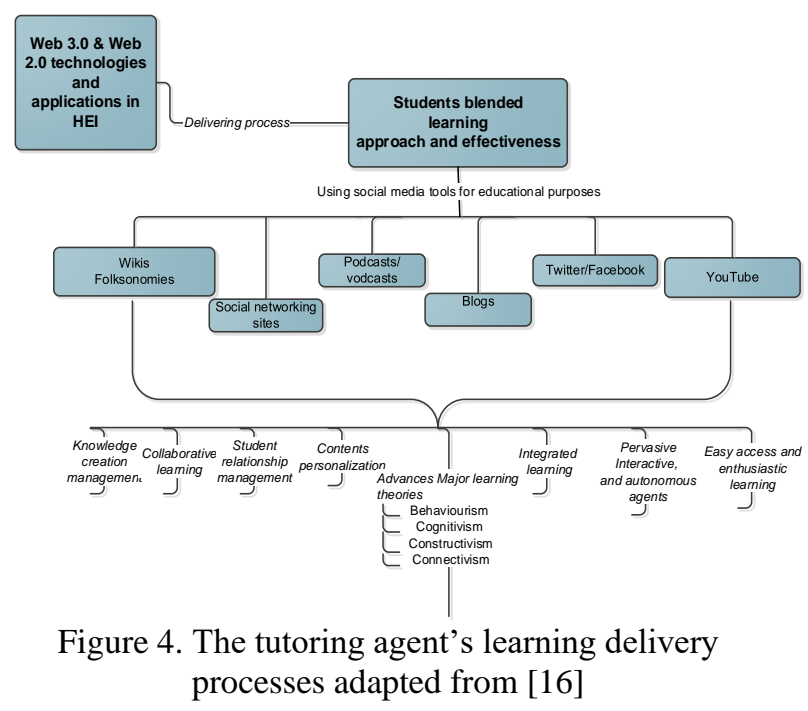

The Figure presented above depicts how these tools and applications encourage knowledge creation management; collaborative learning; students' relationship management; content personalization; improved and integrated learning; pervasive, interactive and autonomous agents; easy access and enthusiastic learning; and improved learning theories (behaviourism, cognitivism, constructivism and connectivism). The literature above offered a brief discussion of the probable benefits of adopting social software / semantic web in education.

There was evidence of educational institutions that have adopted social software / semantic web in their administration and facilitation processes. This section briefly expounds on Figure 4 in relation to web applications as it relates to improving learning theories (specifically connectivism) as it is a more appropriate learning theory for the digital native in an educational setting.

\subsection{Controversies surrounding web 3.0 / web 2.0 technology adoption in HEI.}

The proposed framework above raises security issues in terms of privacy, intellectual property rights; ethical and legal concerns in the event of misuse and exploitation. It also highlights issues that may arise due to human factors, such as technophobia, behavioral pattern, reediness and willingness to adopt new model and approach to facilitation of learning and business processes. Ultimately, concerns with ICT infrastructure were mentioned in the framework.

Several authors [20], [16] argues that some of these issues raised with the use of social software in the public domain needs to be considered as it may prevent or the adoption process. Interacting with students using web instructional technologies and application in a public domain increases the uncertainty of data protection and privacy. One cannot overemphasize those recurring uncertainties, specifically those created by the application tools enabled with social software, concern widespread communication online. These worries tend to focus on the identical issues of falling victim to predatory unidentified outsiders online and augmented victimization by peers.

There have been instances where learners have posted uncomfortable video clips on a media-sharing domain or make unsuitable entries on sites that request learners to rate their educators. The likes of [2] added that inappropriate use of social software / semantic web application tools in education have been undertaken. [2]'s study established that learners' performance deteriorated due to the extensive use of these application tools and using social networking sites. Therefore, spending more time on Facebook appears to result in a deterioration of student scores. In addition, some learners do not use systems such ICT platforms or eLearning platforms judiciously, which in turns results in failure.

The next concepts to be discussed in brief relates to human factors and ICT infrastructure. This section presents highlights of how human behavioral patterns and individual's acceptance or willingness to use educational technologies may influence social software 
adoption process in HEI. The study uses the following theories stated below to unravel the underlining the adoption models. The study will further focus on these theories of adoption as described in [46], [14]'s studies on ICT adoption models and approaches, namely the theory of reasoned action (TRA), theory of planned behavior (TPB), technology of acceptance model (TAM), technology readiness and acceptance model (TRAM) and self-determination theory will be discussed further in the study.

The figure below and the literature shows that there has been substantial activity in IS research. The figure summarizes the issues and concerns authors have in brief. However, these authors have not yet addressed issues with cost, benefits, flexibility and risk in their discussions as part of social software / semantic web \& ICT investment. Again, no author can claim that his or her concept or approach is the most accurate, nor could offer a decisive evidence of the accurateness of their respective approach. Thus, it is appropriate to consider discussing the costs, benefits, risk and flexibility of investing in an ICT investment.

\begin{tabular}{|c|c|c|c|}
\hline Author (s) & Key words & \begin{tabular}{|l|} 
Journal \\
\end{tabular} & Central argument \\
\hline [36] & $\begin{array}{|ll|}\text { Students } & \text { as } \\
\text { producers } & \\
\end{array}$ & $\begin{array}{l}\text { Proceedings } \\
\text { (ITHET) }\end{array}$ & $\begin{array}{l}\text { Personalized and self-regulated } \\
\text { learning }\end{array}$ \\
\hline [37] & $\begin{array}{l}\text { ICT enhancing } \\
\text { quality } \\
\text { education }\end{array}$ & $\begin{array}{lr}\text { Journal } & \text { of } \\
\text { Research } & \text { in } \\
\text { Commerce, } & \text { IT } \\
\text { \& Management }\end{array}$ & $\begin{array}{l}\text { The role of information and } \\
\text { communication technology (ICT) in } \\
\text { enhancing education }\end{array}$ \\
\hline [22] & \begin{tabular}{|l|} 
Social \\
Technologies \\
and informal \\
knowledge \\
gharing
\end{tabular} & \begin{tabular}{|l|} 
Studies- \\
Dissertations
\end{tabular} & $\begin{array}{l}\text { ICT conditions to integrate differences } \\
\text { in learning: Contextual learning theory } \\
\text { and a first trangformation step in early } \\
\text { education }\end{array}$ \\
\hline [47] & $\begin{array}{l}\text { SWOT of using } \\
\text { social goftware } \\
\text { in education }\end{array}$ & $\begin{array}{ll}\text { Journal } & \text { of } \\
\text { Computer } & \\
\text { Assisted } & \\
\text { Learning } & \end{array}$ & $\begin{array}{l}\text { Explore the various implications of } \\
\text { introducing social software into a } \\
\text { course environment in order to identify } \\
\text { the associated benefits, but also the } \\
\text { potential drawbacks. }\end{array}$ \\
\hline [26] & 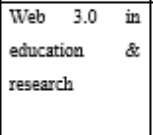 & $\begin{array}{l}\text { Journal of } \\
\text { Information } \\
\text { Technology } \\
\text { BVICAM }\end{array}$ & $\begin{array}{l}\text { The benefit of Web } 3.0 \text { in education } \\
\text { alongside the potential characteristics; } \\
\text { the intelligence, interoperability, } \\
\text { personalization and virtualization }\end{array}$ \\
\hline [12] & \begin{tabular}{|l|} 
An \\
annotation \\
ontology for \\
gcience on web \\
3.0
\end{tabular} & \begin{tabular}{|lr} 
Journal of \\
Biomedical \\
Semantics \\
Proceedings
\end{tabular} & $\begin{array}{l}\text { An investigation to ascertain whether } \\
\text { the annotation ontology meets critical } \\
\text { requirements for an open, freely } \\
\text { ghareable model in OWL, and } \\
\text { annotation metadata created against } \\
\text { scientific documents on the Web }\end{array}$ \\
\hline [3] & \begin{tabular}{|l|} 
e-Commerce \\
business models \\
in the context of \\
Web 3.0 \\
paradigm
\end{tabular} & IJAIT & $\begin{array}{l}\text { Web } 3.0 \text { promises to have a significant } \\
\text { effect on users and businesses }\end{array}$ \\
\hline
\end{tabular}

\begin{tabular}{|c|c|c|c|}
\hline [23] & $\begin{array}{l}\text { E-Leaming } 3.0= \\
\text { E-Leaming } 2.0+ \\
\text { Web } 3.0 ?\end{array}$ & $\begin{array}{l}\text { Conference } \\
\text { (CELDA) }\end{array}$ & $\begin{array}{l}\text { The study describes the way both } \\
\text { previous generations of e-leaning ( } 1.0 \\
\& 2.0 \text { ) emerged with the prevalent } \\
\text { technologies in their kin web versions } \\
\text { (1.0 \& } 2.0 \text { respectively) }\end{array}$ \\
\hline [29]. & $\begin{array}{l}\text { Embracing Web } \\
2.0 \& 3.0 \text { tools to } \\
\text { support lifelong } \\
\text { learning }\end{array}$ & $\begin{array}{l}\text { Procedia r - } \\
\text { Social and } \\
\text { Behavioural } \\
\text { Sciences }\end{array}$ & Learning in a digital age \\
\hline [2] & $\begin{array}{l}\text { Evolution of the } \\
\text { World Wide } \\
\text { Web }\end{array}$ & LdWesT & $\begin{array}{l}\text { Provides a background of the } \\
\text { evolution of the web from web } 1.0 \text { to } \\
\text { web } 4.0\end{array}$ \\
\hline
\end{tabular}

Figure 5. Summary of the issues and concerns related to social software / semantic web

\subsection{Social software and ICT Investment in HEI}

The adoption of social software as an instructional tool in a pedagogical environment is a cause that have attracted much attention [5]. The adoption of social software raises several other issues, while the case for the adoption of instructional web technologies seems convincing, it is apparent to take a closer look at what this entails [1].

Investing in the adoption of social software and ICT tools in Higher Educational Institutes has been motivated based on the business processes. It is important to note that an institution or organization is likely to invest in an ICT investment simply for few reasons, is either an institution wants to improve on quality of service delivery, invent new products or improve on the existing services/products (expansion); to replace or upgrade facilities and assets that have become obsolete (maintenance/upgrade); to reduce costs on current or future expenses (cost displacement); to change the old-style or traditional mode of operation (transformation); and most prominently, to meet the fast changes in technology. Hence the adoption of pedagogical technologies in HEI are for this purposes of maintenance/upgrade, expansion, cost effectiveness and transformation. As indicated in the proposed framework, there are four components of investment assessment, namely costs, benefits, flexibility and the risks (software crises).

These components are not fully address in the discussions by other authors [31], [19] added that when assessing value for money, it is certainly not just about getting involved with the initiative or access to resources. Institutions should reflect on the unforeseen costs of adapting and preparing staff, as well as benefits and flexibility that comes in form of time saving for instance responding to queries or improving one-on-one basic maintenance support, the simplicity of use for learners and the prospect of retention progression from tracking those who struggles.

Authors argues that educational institutes' concentration should be challenged towards advancing business efficiency, quality and competitiveness. Quite a number of issues have emerged. Academic writers have raised issues such as privacy, reputation, identity, 
other cultural crises (beliefs, behavioral patterns). The issues of costs implication, benefits and risk associated with a software crisis and flexibility were not extensively considered in the literature. Institutions should finance ICT investment in the most appropriate way so that it would be value for money, return on investment (ROI), would have benefits and would transform the competitive edge of the business.

According to guidelines as suggested in the above sections, this study will collect a qualitative and quantitative data, which is a combined approach towards data collection and is referred as mixed methods. Data will be collected in this study through audio interviews from the individual interviews and will be analyzed by simple content analysis. Data coding will be used to develop categories.

This reduction of data into themes is a simple but effective form of data analysis that will lead to the identification of these themes. On the other hand, questionnaires will be used to collect information from students across the selected universities. Both approaches qualitative and quantitative data analysis will be consolidated to analysis the results towards developing a comprehensive framework for social software adoption in HEI.

\section{Conclusion}

This study laid the foundation for the study by presenting the introduction in form of background context, the research problem, identifying the research objective. Furthermore, gave an overview of a framework for social software adoption in HEI in the form of a literature that detailed and unveiled the theoretical perspectives that are of relevance to the study based on previous scholars' experience of how similar research problems were solved. It again, presented the research design and methods, it offered a clear discussion of research processes, approaches and theoretical paradigms and as well as techniques, that the study intends to adopt during this study. A detailed discussion on the proposed conceptual framework. Ultimately, the research problem identified in the study will be solve and the objectives will be attained. Solutions will emerge through the comprehensive framework based on the mixed method research approach.

Substantially, this study offered a planned methodological concept to develop and test framework for social software adoption in HEI. This research will establish an effective feedback process of information that could potentially be exchanged across these selected universities. After research have been conducted, social software adoption will be based on the adapted comprehensive framework that will serve as complimentary tools to support teaching and learning, not as a replacement of the traditional method, but as a blended approach.
Given the distinguishing features of Web 3.0/ Web 2.0 , educators and students could potentially gain the skills and knowledge required to better prepare them in the use of instructional ICT web technology and application in HEI. It may serve as tools for students to effectively manage and administer their own teaching and learning practices. Setting their respective ambitions and making sustainable decisions concerning education [23], [12].

These tools and applications will indefinitely impact positively on learners' performance, knowledge acquisition and advancement in ICT use. Ultimately, intelligent agents and personal assistants could be people's companions in education. Then, and only then, the Web 3.0/ Web 2.0 will have become a reality in HEI.

\section{Acknowledgment}

This research acknowledges the support rendered by the Institutional Bursary Scholarship, North West University who gave financial support in advancing this project. The authors would like to than Prof Sam Lubbe and Prof Nehemiah Mavetera who provided expertise that assistance towards the research.

\section{References}

[1] Abousoliman, O. (2017). Integrating social networks in teaching in higher education. Biola University.

[2] Aghaei, S., Nematbakhsh, M. A. \& Farsani, H. K. (2012). Evolution of the World Wide Web: From WEB 1.0 TO WEB 4.0. International Journal of Web \& Semantic Technology, $3(1), 1$.

[3] Al-Alwani, A. (2005). Barriers to integrating information technology in Saudi Arabia science educatio. Kansas: The University of Kansas (Doctoral dissertation).

[4] Almeida, F., Santos J.D. \& Monteiro, J.A. (2013). ECommerce business models in the context of Web 3.0 paradigm. International Journal of Advanced Information Technology, 3(6):1-12

[5] Angeli, C., Valanides, N., Mavroudi, A., Christodoulou, A. \& Georgiou, K. (2015). Introducing e-TPCK: An adaptive e-learning technology for the development of teachers' technological pedagogical content knowledge. In Technological pedagogical content knowledge (pp. 305-317). Springer, Boston, MA.

[6] Balanskat, A., Blamire, R., \& Kefala, S. (2006). The ICT impact report. European Schoolnet, 1:1-71.

[7] Bingimlas K.A. (2009). Barriers to successful integration of ICT in teaching and learning environments: A review of the literature. Eurasia Journal of Mathematics, Science \& Technology Education, 5(3):235-245.

[8] Bingimlas, K. (2018). Investigating the level of teachers' Knowledge in Technology, Pedagogy, and Content (TPACK) in Saudi Arabia. South African Journal of Education, 38(3). 
[9] Buabeng-Andoh, C. (2012). Factors influencing teachers' adoption and integration of information and communication technology into teaching: A review of the literature. International Journal of Education and Development using Information and Communication Technology, 8(1):136-155.

[10] Chawinga, W. D., \& Zinn, S. (2016). Use of Web 2.0 by students in the Faculty of Information Science and Communications at Mzuzu University, Malawi. South African Journal of Information Management, 18(1), 1-12.

[11] Chetty, D. (2012). Challenges and prospects: ICTenhanced teaching and learning in the College of Human Sciences (Unisa). 5th International Conference of Education, Research and Innovation, pp.3618-3627.

[12] Chisega-Negrila, A.M. (2012). Web 3.0 in education. The eighth International Scientific Conference eLearning and software for Education Bucharest. Central and Eastern European Online Library, 1:455-460.

[13] Creswell, J.W. (2015). A concise introduction to mixed methods research. Thousand Oaks, CA: Sage.

[14] Davis, F.D., Bagozzi, R.P. \& Warshaw, P.R. (1989). User acceptance of computer technology: A comparison of two theoretical models. Management Science, 35(8):982-1003.

[15] Davis, N., Preston, C. \& Sahin, I. (2009). Training teachers to use new technologies impacts multiple ecologies: Evidence from a national initiative. British Journal of Educational Technology, 40(5):861-878.

[16] Dotsika, F. (2012). The next generation of the web: an organisational perspective. Working Paper, University of Westminster. Series in Business and Management, University of Westminster, London.

[17] Ertmer, P.A. \& Ottenbreit-Leftwich, A.T. (2010). Teacher technology change: How knowledge, confidence, beliefs, and culture intersect. Journal of research on Technology in Education, 42(3):255-284.

[18] Gray, K., Chang, S. \& Kennedy, G. 2010. Use of social web technologies by international and domestic undergraduate students: implications for internationalising learning and teaching in Australian universities. Technology, Pedagogy and Education, 19:31-46.

[19] Haigh, C.A. (2010). Reconstructing nursing altruism using a biological evolutionary framework. Journal of Advanced Nursing, 66(6):1401-1408.

[20] Hamadani Janes, S., Patrick, K. \& Dotsika, F. (2014). Implementing a social intranet in a professional services environment through Web 2.0 technologies. The Learning Organization, 21(1), 26-47.

[21] Hennessy, S., Wishart, J., Whitelock, D., Deaney, R., Brawn, R., La Velle, L., McFarlane, A., Ruthven, K. \& Winterbottom, M. (2007). Pedagogical approaches for technology - integrated science teaching. Computers \& Education, 48(1):137-152.

[22] Hooker, M., Mwiyeria, E. \& Verma, A. (2011). ICT competency framework for teachers in Nigeria, teacher development for the 21st Century (TDev21) pilot a national commission for colleges of education Nigeria. World Bank and GESCI Initiative.

[23] Hussain, F. (2012). E-learning $3.0=$ E-learning $2.0+$ WEB 3.0? IADIS International Conference on Cognition and Exploratory Learning in Digital Age (CELDA 2012).

[24] International Society for Technology in Education. (2002). National educational technology standards for teachers: preparing teachers to use technology. Danvers, MA: ISTE.

[25] Jaffer, S., Ng'ambi, D. \& Czerniewicz, L. (2007). The role of ICTs in higher education in South Africa: one strategy for addressing teaching and learning challenges. International Journal of Education and Development using Information and Communication Technology, 3(4):131-142.

[26] Jimoyiannis, A., Tsiotakis, P., Roussinos, D. \& Siorenta, A. (2013). Preparing teachers to integrate Web 2.0 in school practice: Toward a framework for Pedagogy 2.0. Australasian Journal of Educational Technology, Vol. 29 (2).

[27] Kanvaria, V.K. (2013). Skill development and professional development of teacher educators on and through Open Education Resources (OER). University of Delhi, India

[28] Korte, W.B. \& Hüsing, T. (2007). Benchmarking access and use of ICT in European schools 2006: Results from Head Teacher and A Classroom Teacher Surveys in 27 European countries. eLearning Papers, 2(1):1-6.

[29] Kwanya, T., Stilwell, C. \& Underwood, P. (2012). The application of Web 2.0 tools by libraries in Kenya: a reality check. In SCECSAL XXth Conference (pp. 4-8).

[30] Lal, M. (2011). Web 3.0 in Education \& Research. BVICAM's International Journal of Information Technology, $3(2)$.

[31] Lefever, R. \& Currant, B. (2010). How can technology be used to improve the learner experience at points of transition. Higher Education Academy.

[32] Louw, J. S. (2017). The development of a framework for the use of Information and Communication Technology in the classroom (Doctoral dissertation, Bloemfontein: Central University of Technology, Free State).

[33] Madhukar, B.S. (2013). Innovations in education for knowledge society role of ICT in Education. Scholarly Research Journal for Interdisciplinary Studies.

[34] Makura, A. H. (2014). Students' perceptions of the use of ICT in a higher education teaching and learning context: The case of a South African University. Mediterranean Journal of Social Sciences, 5(11), 43.

[35] Marshall, S., Taylor, W., Moakofhi, M. K., Leteane, O., Phiri, T. V., Pholele, T. M. \& Çakır, A. (2017). The role of ICT in supporting various learning environments. International Journal of Education and Development using Information and Communication Technology, 13(2), 2. 
[36] McCauley, K. (2016). Computer Animation in Instructional Design. In Society for Information Technology \& Teacher Education International Conference (pp. 21852190). Association for the Advancement of Computing in Education (AACE).

[37] McEneaney, J. E. (2011). Web 3.0, litbots, and TPWSGWTAU. Journal of Adolescent \& Adult Literacy, 54(5), 376-378.

[38] McLoughlin, C. \& Lee, M. J. (2010). Personalised and self-regulated learning in the Web 2.0 era: International exemplars of innovative pedagogy using social software. Australasian Journal of Educational Technology, 26(1), 2843.

[39] Moges, B. (2013). The role of information and communication technology (ICT) in enhancing the quality education of Ethiopian universities: a review of literature. Journal of Education Research and Behavioral Sciences, 3(8):246-258.

[40] Motala, I. \& Padayachee, I. (2018). Readiness to Adopt the Internet of Things at the University of KwaZulu-Natal. In ICEL 2018 13th International Conference on e-Learning (p. 256). Academic Conferences and publishing limited.

[41] Noor Ul Amin, S. (2013). An effective use of ICT for education and learning by drawing on worldwide knowledge, research, and experience: ICT as a Change Agent for Education (A Literature review). Scholarly Journal of Education, 2(4):38-45.

[42] Nwosu, O. \& Ogbomo, E.F. (2012). ICT in Education: A catalyst for effective use of information. The official publication of the Pacific Northwest library Association PNLA Quarterly. http:// www.ict in education: as a catalyst for effective use of information Date of access: 28 Jun. 2011.

[43] O'Reilly, T. (2005). What is Web 2.0: Design patterns and business models for the next generation of software, communications \& strategies, 1(65):17

[44] Ohei, K. and Lubbe, S., 2013. November. Social Differences between Information Systems Students and NonInformation Systems Students at North West University (Mafikeng Campus). In Information Technology and Applications (ITA), 2013 International Conference on (pp. 180-184). IEEE.

[45] Ohei, K., Lubbe, S., Meyer, J. and Klopper, R., 2015. Views about Information Systems among North West University Mafikeng Campus Management, Administration and Law Students. South African Research in Management, Informatics and Governance in a 21st Century Hyper Connected World, p.233.

[46] Omona, W., Van der Weide, T. \& Lubega, J. (2010). Using ICT to enhance knowledge management in higher education: A conceptual framework and research agenda. International Journal of Education and Development using Information and Communication Technology, 6(4):83.

[47] Özden, M. (2007). Problems with science and technology education in Turkey. Eurasia Journal of Mathematics, Science \& Technology Education, 3(2):157-161.
[48] Ozer, B. (2013). Teacher profile, teacher education and teacher professionalization in Turkey. Proceedings of the 37th Annual Conference of ATEE in Eskisehir, 25th -29th August 2012.

[49] Pileggi, S.F., Fernandez-Llatas, C. \& Traver, V. (2012). When the social meets the semantic: Social semantic web or web 2.5. Future Internet, 4:852-864.

[50] Roehrig, G.H., Kruse, R.A. \& Kern, A. (2007). Teacher and school characteristics and their influence on curriculum implementation. Journal of Research in Science Teaching, 44:883-907.

[51] Schoepp, K. (2005). Barriers to technology integration in a technology-rich environment. Learning and Teaching in Higher Education: Gulf Perspectives, 2(1):1-24

[52] Wastiau, P., Blamire, R., Kearney, C., Quittre, V., Van de Gaer, E. \& Monseur, C. (2013). The use of ICT in education: a survey of schools in Europe. European Journal of Education, 48(1):11-27.

[53] Wood, L.W. (2015). Faculty perceptions about virtual world technology: Affordances and barriers to adoption. Dissertation, Georgia State University. 